\title{
Allogeneic Suppressive Effects of Pregnancy Sera on Monocytes of Responding Cells in Human Mixed Lymphocyte Reactions
}

\author{
Mie Nieda, Takeo Juji, and Sadao Imao \\ Blood Transfusion Service, Tokyo Women's Medical College, Tokyo 162, Japan
}

\begin{abstract}
The purified human monocytes of a responding donor preincubated with heat-inactivated serum T1264 or T1295 derived from pregnant women for $30 \mathrm{~min}$ at $37^{\circ} \mathrm{C}$ expressed allogeneic suppressive effects on the proliferative response of the lymphocytes from the same donor in the allogeneic mixed lymphocyte reaction (MLR). The pregnancy serum in our experiments was found not to contain any antibodies to DR and DQ antigens on monocytes of the responding donor. Accordingly, the suppressive effects mediated by monocytes were not based on the blocking of DR and DQ antigens on monocytes of the responding donor by DR and DQ antibodies in the serum. These highly reproducible allogeneic suppressive effects by monocytes of the responding donor were demonstrated in the MLR specific for DRw9-positive stimulating cells, whereas no inhibition was seen in the cultures with other stimulating cells of different DR phenotypes. Additionally, these suppressive effects appeared on the monocytes of a DR2positive responding donor, but not on the monocytes of a DR2negative responding donor. These suppressive effects were abolished when the absorbed pregnancy serum by monocytes of the DR2-positive responding donor was used. In this suppression phenomenon that we discovered, monocytes of the responding donor appear to act as regulatory cells on the proliferative response of the allogeneic MLR. This regulatory function of monocytes could be expressed through the specific molecules distinct from DR and DQ determinants on monocytes in cooperation with antibodies (IgG class) in the pregnancy serum.
\end{abstract}

\section{Introduction}

Humoral and cell-mediated immune responses are subject to regulatory control through a variety of suppressor mechanisms. In studies on mice, a subpopulation of thymus-derived ( $T$ ) lymphocytes that express Ly2 and 3 antigens (1), a substance released from macrophages (2), a membrane component of macrophages (3), certain IgM antibodies (4), and antiidiotypic antibodies (5) is known to suppress a variety of immune responses. Cortisonesensitive cells that adhere to glass wool suppress $\left[{ }^{3} \mathrm{H}\right]$ thymidine incorporation in stimulated cultures of rat spleen cells $(6,7)$. Furthermore, in humans, the regulatory function of $\mathrm{T}$ cell subsets (suppressor T cells) on the proliferative response in allogeneic mixed lymphocyte reaction (MLR) ${ }^{1}$ has been confirmed $(8,9)$.

Received for publication 13 November 1984 and in revised form 17 June 1985.

1. Abbreviations used in this paper: MLR, mixed lymphocyte reaction; NHS, normal human AB serum.

J. Clin. Invest.

(c) The American Society for Clinical Investigation, Inc. $0021-9738 / 85 / 10 / 1477 / 08 \$ 1.00$

Volume 76, October 1985, 1477-1484
In these studies, the suppressor $\mathrm{T}$ cells inhibited the response of individuals who shared HLA Dw specificity with responding cells.

There is considerable evidence that macrophages broadly inhibited the $\mathrm{T}$ cell proliferation to $\mathrm{B}+$ null cells in a dosedependent fashion throughout the time course of the autologous MLR (10), although the nature of macrophages in responding cells remains controversial. Also in the allogeneic MLR, the lymphoproliferation was nonspecifically suppressed in the presence of high concentrations of mononuclear cells in which the suppressor cells might have been one of the monocyte series (11).

Many reports (12-20) have already been published on the role of peripheral blood monocytes in the MLR. In these studies, stimulating or responding cell samples in which monocytes were enriched or depleted were used. Especially, Mann and Abelson (21) have demonstrated that monocytes present in the stimulating or responding cell population were necessary for lymphocyte proliferation in the MLR and that this proliferative response was inhibited by alloimmune sera, which reacted to the DR antigens on monocytes of the responding cell population.

Other studies $(22,23)$ have demonstrated that alloimmune sera markedly inhibited in vitro immune responses. Muchmore et al. (22) have suggested that monocytes treated with anti-DR antisera appeared to suppress the ability of antigen-pulsed monocytes to stimulate antigen-specific proliferation of $T$ cells.

During the examination of pregnancy sera, we found that allogeneic suppressive effects in MLR were expressed by purified monocytes incubated with the sera for a fixed period of time and then washed completely. Sera T1264 and T1295 in these experiments were found not to contain any antibodies to DR and DQ antigens on responding cells. The suppressive effects of the sera were demonstrated only on MLR, in which the phenotypes of the stimulators were HLA-DRw9 positive, whereas these suppressive effects on MLR were not observed if the stimulators were DRw9 negative. Moreover, these suppressive effects appeared on monocytes of a DR2-positive responding donor, but not on monocytes of a DRw8-positive or a DR1-positive responding donor.

In this paper, the possible roles of monocytes and factors in pregnancy sera on allogeneic MLR will be discussed.

\section{Methods}

Blood samples were obtained from a panel of healthy persons known to be homozygous or heterozygous for HLA antigens.

Sera. Pregnancy sera T1264 and T1295 were examined after absorption with pooled platelets. Serum T1264 contained antibodies to DR7 and DRw9, and serum T1295 contained antibodies to DR4 and DRw9.

Preparation of cells. Mononuclear cells were isolated from fresh venous blood by centrifugation with a Ficoll-Hypaque gradient. These cells were resuspended in RPMI 1640 medium containing $10 \%$ pooled normal human $\mathrm{AB}$ serum (NHS) and were plated in a glass petri dish at $37^{\circ} \mathrm{C}$ 
Table I. The Suppressive Effects of One-Way MLR by Preincubation of Monocytes of Responding Donor M.N. with Pregnancy Serum T1264

\begin{tabular}{|c|c|c|c|c|c|}
\hline \multicolumn{3}{|l|}{ Stimulator } & \multicolumn{3}{|c|}{ Responder M.N. (DR2,2; DQw1,1) } \\
\hline HLA & DR & DQw & Monocytes/NHS* (control) & Monocytes/T1264‡ & \% Suppression \\
\hline 1. H.H. & $(w 9, w 9)$ & $(w 3, w 3)$ & $22,917 \pm 1,095$ & $3,975 \pm 1,378$ & $83 \S$ \\
\hline 2. H.R. & $(w 9, w 9)$ & $(w 3, w 3)$ & $20,893 \pm 2,104$ & $3,261 \pm 1,051$ & $84 \S$ \\
\hline 3. K.M. & $(w 9,-)$ & $(w 3,-)$ & $18,550 \pm 927$ & $4,282 \pm 256$ & $77^{\prime \prime}$ \\
\hline 4. H.S. & $(w 9,-)$ & $(w 3,-)$ & $16,624 \pm 531$ & $3,336 \pm 958$ & $80^{\prime \prime}$ \\
\hline 5. S.T. & $(4, w 9)$ & $(w 3, w 3)$ & $17,131 \pm 2,991$ & $3,258 \pm 670$ & $81^{11}$ \\
\hline 6. J.U. & $(4, w 9)$ & $(w 3, w 3)$ & $22,384 \pm 4,904$ & $10,688 \pm 1,161$ & $52^{11}$ \\
\hline 7. T.A. & $(2, w 9)$ & $(w 1, w 3)$ & $14,980 \pm 836$ & $5,202 \pm 2,828$ & $65^{\prime \prime}$ \\
\hline 8. M.U. & $(w 9, w 13)$ & $(w 1, w 3)$ & $17,437 \pm 2,019$ & $8,316 \pm 591$ & $52^{\prime \prime}$ \\
\hline 9. T.O. & $(w 9, w 8)$ & $(w 1, w 3)$ & $23,850 \pm 985$ & $12,182 \pm 2,635$ & $49^{\prime \prime}$ \\
\hline 10. O.D. & $(w 8,-)$ & $(w 1,-)$ & $12,347 \pm 596$ & $12,885 \pm 1,326$ & -4 \\
\hline 11. S.G. & $(w 8,-)$ & $(w 1,-)$ & $22,417 \pm 7,823$ & $20,184 \pm 7,599$ & 10 \\
\hline 12. S.M. & $(1, w 8)$ & $(w 1,-)$ & $17,820 \pm 3,010$ & $16,230 \pm 1,058$ & 9 \\
\hline 13. S.O. & $(4,-)$ & $(w 3,-)$ & $14,567 \pm 3,316$ & $11,496 \pm 3,201$ & 21 \\
\hline 14. Y.N. & $(4,-)$ & $(w 3,-)$ & $12,077 \pm 926$ & $13,425 \pm 1,536$ & -11 \\
\hline 15. M.A. & $(2,4)$ & $(w 1, w 3)$ & $21,251 \pm 2,872$ & $16,455 \pm 1,897$ & 23 \\
\hline 16. Y.A. & $(2,4)$ & $(\mathrm{w} 1, \mathrm{w} 3)$ & $27,109 \pm 3,917$ & $20,991 \pm 6,534$ & 23 \\
\hline 17. S.F. & $(w 13,-)$ & $(w 1,-)$ & $10,080 \pm 3,911$ & $75,578 \pm 632$ & 25 \\
\hline 18. N.F. & $(2,-)$ & $(w 1,-)$ & $27,412 \pm 1,760$ & $22,684 \pm 3,082$ & 17 \\
\hline 19. M.N. & $(2,2)$ & $(w 1, w 1)$ & $154 \pm 120$ & $170 \pm 55$ & -10 \\
\hline
\end{tabular}

Lymphocytes with preincubated monocytes as responder were co-cultured with mitomycin C-treated mononuclear cells of several allogeneic stimulators in MLR. * Response (cpm) in the presence of monocytes preincubated with NHS. $¥$ Response (cpm) in the presence of monocytes preincubated with serum T1264. § Significant suppression, $P<0.001$. "Significant suppression, $P<0.02$.

for $30 \mathrm{~min}$ to allow monocytes to adhere to the glass surface. Thereafter, the nonadherent cells ( $\mathrm{T}$ and $\mathrm{B}$ lymphocytes) were harvested by gentle pipetting. After the dish wàs allowed to stand at $4^{\circ} \mathrm{C}$ for $>1 \mathrm{~h}$, monocytes that had adhered to the glass surface were collected by vigorous pipetting with a cold medium. The purity of the collected monocytes was examined using three different methods: ( $a$ ) a microscope after nonspecific esterase staining, $(b)$ a binding test with monoclonal antibody Leu M3, using a flow cytofluorometer, and $(c)$ a monocyte cytotoxicity test using mono-

Table II. The Suppressive Effects of One-Way MLR by Preincubation of Monocytes of Responding Donor M.N. with Pregnancy Serum T1295

\begin{tabular}{|c|c|c|c|c|c|}
\hline \multicolumn{3}{|l|}{ Stimulator } & \multicolumn{3}{|c|}{ Responder M.N. (DR2,2; DQw1,1) } \\
\hline HLA & DR & $\mathrm{DQw}$ & Monocytes/NHS* (control) & Monocytes/T1295‡ & \% Suppression \\
\hline 1. H.H. & $(w 9, w 9)$ & $(w 3, w 3)$ & $13,582 \pm 2,014$ & $690 \pm 320$ & $95 \S$ \\
\hline 2. H.R. & $(w 9, w 9)$ & $(w 3, w 3)$ & $18,527 \pm 1,563$ & $1,655 \pm 906$ & $91 \S$ \\
\hline 3. K.M. & $(w 9,-)$ & $(w 3,-)$ & $23,166 \pm 4,502$ & $8,702 \pm 1,006$ & $62^{11}$ \\
\hline 4. H.S. & $(w 9,-)$ & $(w 3,-)$ & $17,142 \pm 4,832$ & $5,681 \pm 3,130$ & $67^{11}$ \\
\hline 5. S.T. & $(4, w 9)$ & (w3,w3) & $19,715 \pm 3,788$ & $9,568 \pm 3,942$ & $51^{11}$ \\
\hline 6. J.U. & $(4, w 9)$ & (w3,w3) & $19,853 \pm 2,097$ & $9,306 \pm 1,265$ & $53^{\prime \prime}$ \\
\hline 7. T.A. & $(2, w 9)$ & $(w 1, w 3)$ & $14,980 \pm 836$ & $5,632 \pm 2,107$ & $62^{\prime \prime}$ \\
\hline 8. M.U. & $(w 9, w 13)$ & $(w 1, w 3)$ & $11,624 \pm 3,634$ & $3,242 \pm 1,081$ & $72^{\prime \prime}$ \\
\hline 9. T.O. & $(w 9, w 8)$ & $(w 1, w 3)$ & $23,850 \pm 985$ & $6,722 \pm 2,530$ & $72^{\prime \prime}$ \\
\hline 10. O.D. & $(w 8,-)$ & $(w 1,-)$ & $12,347 \pm 596$ & $12,271 \pm 1,023$ & 1 \\
\hline 11. S.G. & $(w 8,-)$ & $(w 1,-)$ & $16,881 \pm 2,003$ & $18,022 \pm 1,564$ & -7 \\
\hline 12. S.M. & $(1, w 8)$ & $(w 1,-)$ & $19,359 \pm 1,056$ & $15,854 \pm 1,011$ & 18 \\
\hline 13. S.O. & $(4,-)$ & $(w 3,-)$ & $10,721 \pm 1,974$ & $10,980 \pm 1,449$ & -2 \\
\hline 14. Y.N. & $(4,-)$ & $(w 3,-)$ & $14,037 \pm 1,026$ & $13,194 \pm 1,006$ & -6 \\
\hline 15. M.A. & $(2,4)$ & (w1,w3) & $14,149 \pm 2,593$ & $11,106 \pm 1,123$ & 22 \\
\hline 16. Y.A. & $(2,4)$ & (w1,w3) & $11,817 \pm 3,856$ & $10,980 \pm 2,056$ & 7 \\
\hline 17. I.F. & $(2, w 13)$ & $(w 1, w 1)$ & $14,780 \pm 2,146$ & $14,891 \pm 998$ & -1 \\
\hline 18. W.A. & $(4, w 8)$ & $(w 1, w 3)$ & $19,774 \pm 3,761$ & $16,937 \pm 3,015$ & 14 \\
\hline 19. M.N. & $(2,2)$ & $(w 1, w 1)$ & $206 \pm 105$ & $214 \pm 117$ & -4 \\
\hline
\end{tabular}

Lymphocytes with preincubated monocytes as responder were co-cultured with mitomycin C-treated mononuclear cells of several allogeneic stimulators in MLR. * Response (cpm) in the presence of monocytes preincubated with NHS. $¥$ Response (cpm) in the presence of monocytes preincubated with the serum T1295. § Significant suppression, $P<0.001$. "Suppression, $P<0.02$. 
Table III. No Suppressive Effects of One-Way MLR by Preincubation of T Cells of Responding Donor M.N. with Pregnancy Serum T1295

\begin{tabular}{|c|c|c|c|c|}
\hline $\begin{array}{l}\text { Responder M.N. } \\
\text { (DR2,2; DQw1,1) }\end{array}$ & $\begin{array}{l}\text { Stimulator H.R. } \\
\text { (DRw9,w9; DQw3,w3) }\end{array}$ & \% Suppression & $\begin{array}{l}\text { Stimulator O.D. } \\
\text { (DRw8,-; DQw1,-) }\end{array}$ & \% Suppression \\
\hline \multicolumn{5}{|l|}{ Experiment 1} \\
\hline $\mathrm{L}+\mathrm{M} / \mathrm{NHS}^{*}$ (control) & $17,132 \pm 2,091$ & & $20,291 \pm 2,796$ & \\
\hline$L+M / 1295 \ddagger$ & $3,178 \pm 938$ & $81 \S$ & $18,429 \pm 2,132$ & 9 \\
\hline \multicolumn{5}{|l|}{ Experiment 2} \\
\hline L/NHS ${ }^{*}+M$ (control) & $19,563 \pm 3,072$ & & $24,363 \pm 3,258$ & \\
\hline$L / 1295 \ddagger+M$ & $17,504 \pm 1,826$ & 10 & $27,189 \pm 2,857$ & -11 \\
\hline \multicolumn{5}{|l|}{ Experiment 3} \\
\hline $\mathrm{T} / \mathrm{NHS}^{*}+\mathrm{B}+\mathrm{M}$ (control) & $22,016 \pm 2,914$ & & $22,994 \pm 3,072$ & \\
\hline $\mathrm{T} / 1295 \ddagger+\mathrm{B}+\mathrm{M}$ & $18,968 \pm 1,127$ & 14 & $26,770 \pm 1,056$ & -16 \\
\hline
\end{tabular}

In experiment 1, each preincubated monocyte preparation of responding donor M.N. was reconstituted with lymphocytes (nonadherent cells) from the same donor at the ratio 1:10. In experiment 2, each preincubated lymphocyte preparation was reconstituted with monocytes at the ratio 10:1. In experiment 3, each preincubated $T$ cell preparation was reconstituted with monocytes and $B$ cells at the ratio 10:1:1. Monocytes (M), lymphocytes (L), and T cells (T) were preincubated with NHS* and serum T1295‡, respectively. $\S$ Significant suppression, $P<0.001$.

clonal antibody OKM 1 . The monocyte preparations used were $>95 \%$ pure. The nonadherent cells were separated into enriched $T$ cells and $B$ cells using a nylon wool method described by Danilovs et al. (24) with some modifications. More than $95 \%$ of the separated T cells were killed by monoclonal antibody OKT3 in a complement-dependent cytotoxicity assay.

Treatment of monocytes. Monocytes separated by the above-described procedure were preincubated for $30 \mathrm{~min}$ at $37^{\circ} \mathrm{C}$ with a heat-inactivated pregnancy serum and pooled NHS (control), at the ratio of $400 \mu \mathrm{l}$ serum to $1 \times 10^{6}$ monocytes, and then washed three times with RPMI 1640 medium.

Mixed lymphocyte cultures. RPMI 1640 medium supplemented with pooled NHS at $20 \%$ was used throughout as the culture medium. The $1 \times 10^{5}$ preincubated monocytes were mixed with $1 \times 10^{6}$ nonadherent cells of the same donor at approximately the original cell ratio. These reconstituted mononuclear cells were resuspended at $1 \times 10^{6}$ cells $/ \mathrm{ml}$ in RPMI 1640 medium and used as responding cells. Stimulating cells were treated with mitomycin $\mathrm{C}$ and prepared at a concentration of
$1 \times 10^{6} \mathrm{cells} / \mathrm{ml}$ in RPMI 1640 medium. Mixed lymphocyte cultures were carried out in a round-bottomed microtiter tray with 50,000 responding cells and 50,000 mitomycin C-treated stimulating cells in 100 $\mu \mathrm{l}$ of medium. The mixed cells were incubated in a $0.5 \% \mathrm{CO}_{2}$ humidified air incubator for $6 \mathrm{~d}$ at $37^{\circ} \mathrm{C}$. $\left[{ }^{3} \mathrm{H}\right] \mathrm{Thymidine}(0.6 \mu \mathrm{Ci} /$ well $)$ was added to each well, and the cells were harvested in a harvester (Labo Science Comp. Ltd., Tokyo, Japan) $3 \mathrm{~h}$ later. $\left[{ }^{3} \mathrm{H}\right]$ Thymidine incorporation was measured in a liquid scintillation counter. The cultures were set up in triplicate, and the results were expressed as the mean counts per minute \pm SE of this triplicate.

Absorption test with monocytes or B lymphocytes. A pregnancy serum was absorbed with monocytes and B lymphocytes, respectively, at the ratio of $1 \mu \mathrm{l}$ serum per $5 \times 10^{4}$ cells for $30 \mathrm{~min}$ at $22^{\circ} \mathrm{C}$.

Fractionation of pregnancy serum. Pregnancy serum T1295 was fractionated using high performance liquid chromatography. An aliquot of fivefold-diluted pregnancy serum T1295 $(5 \mathrm{ml})$ was applied to anion exchange column Mono Q (Pharmacia Fine Chemicals, Piscataway, NJ). After the serum application, the column was washed with three bed

Table IV. No Suppressive Effects of One-Way MLR by Preincubation of Monocytes of Responding Donor O.D. with Pregnancy Serum T1264

\begin{tabular}{|c|c|c|c|c|c|}
\hline \multicolumn{3}{|l|}{ Stimulator } & \multicolumn{3}{|c|}{ Responder O.D. (DRw8,-; DQw1,-) } \\
\hline HLA & $\mathrm{DR}$ & $\mathrm{DQw}$ & Monocytes/NHS* (control) & Monocytes/T1264ł & \% Suppression \\
\hline 1. H.H. & $(w 9, w 9)$ & (w3,w3) & $20,141 \pm 3,185$ & $20,194 \pm 2,098$ & 0 \\
\hline 2. H.R. & $(w 9, w 9)$ & (w3,w3) & $14,749 \pm 2,021$ & $16,704 \pm 3,236$ & 13 \\
\hline 3. S.T. & $(4, w 9)$ & $(w 3, w 3)$ & $17,901 \pm 3,015$ & $16,001 \pm 2,143$ & 11 \\
\hline 4. J.U. & $(4, w 9)$ & (w3,w3) & $13,106 \pm 1,159$ & $14,799 \pm 1,966$ & -13 \\
\hline 5. T.A. & $(2, w 9)$ & $(w 1, w 3)$ & $21,253 \pm 4,122$ & $20,164 \pm 4,311$ & 5 \\
\hline 6. T.O. & $(w 8, w 9)$ & $(w 1, w 3)$ & $23,166 \pm 2,804$ & $21,702 \pm 1,917$ & 6 \\
\hline 7. T.J. & $(w 9, w 12)$ & (w3,w3) & $11,986 \pm 2,691$ & $11,218 \pm 2,133$ & 6 \\
\hline 8. S.O. & $(4,-)$ & $(w 3,-)$ & $19,761 \pm 3,100$ & $16,264 \pm 1,050$ & 18 \\
\hline 9. N.A. & $(4,-)$ & $(w 3,-)$ & $19,674 \pm 1,198$ & $21,033 \pm 6,008$ & -7 \\
\hline 10. A.R. & $(4,-)$ & $(w 3,-)$ & $15,733 \pm 2,956$ & $13,602 \pm 1,136$ & 14 \\
\hline 11. Y.A. & $(2,4)$ & $(w 1, w 3)$ & $25,811 \pm 2,954$ & $26,374 \pm 3,057$ & -2 \\
\hline 12. M.S. & $(2, w 8)$ & $(w 1, w 1)$ & $26,067 \pm 4,311$ & $23,160 \pm 2,168$ & 11 \\
\hline 13. M.N. & $(2,2)$ & $(w 1, w 1)$ & $26,212 \pm 2,007$ & $21,967 \pm 1,757$ & 16 \\
\hline 14. O.D. & $(w 8,-)$ & $(w 1,-)$ & $244 \pm 120$ & $206 \pm 31$ & 16 \\
\hline
\end{tabular}

Lymphocytes with preincubated monocytes as responder were co-cultured with mitomycin C-treated mononuclear cells of several allogeneic stimulators in MLR. * Response (cpm) in the presence of monocytes preincubated with NHS. $¥$ Response (cpm) in the presence of monocytes preincubated with serum T1264. 
Table V. The Absorption Experiments of Pregnancy Serum T1264 with Monocytes of Responding Donor M.N.

\begin{tabular}{lcccc}
\hline $\begin{array}{l}\text { Responder M.N. } \\
\text { (DR2,2; DQw1,1) }\end{array}$ & $\begin{array}{l}\text { Stimulator K.M. } \\
\text { (DRw9,-; DQw3,-) }\end{array}$ & \% Suppression & $\begin{array}{l}\text { Stimulator S.O. } \\
\text { (DR4,-; DQw3,-) }\end{array}$ & \% Suppression \\
\hline Lymphocytes + M/NHS* & $13,582 \pm 2,164$ & & $21,579 \pm 2,026$ & \\
Lymphocytes + M/1264‡ & $5,540 \pm 1,009$ & $59^{\| 1}$ & $16,217 \pm 896$ & 25 \\
Lymphocytes + M/1254 M.A.§ & $10,265 \pm 965$ & 24 & $16,054 \pm 1,059$ & 26 \\
\hline
\end{tabular}

* Monocytes preincubated with NHS (control). ‡ Monocytes preincubated with serum T1264. § Monocytes preincubated with the absorbed serum T1264 by monocytes from a responding donor M.N. Each monocyte preparation of responding donor M.N. was reconstituted with lymphocytes from the same donor. These reconstituted mononuclear cells as responding cells were co-cultured with stimulating cells. "Suppression, $P<0.02$.

volumes of starting buffer $(0.05 \mathrm{M}$ Tris- $\mathrm{HCl}, \mathrm{pH} 8.6)$ before initiation of a linear $0.0-0.5 \mathrm{M} \mathrm{NaCl}$ gradient. Proteins were detected spectrophotometrically at $280 \mathrm{~nm}$. Each protein peak was collected, concentrated to the starting volume, dialyzed against RPMI medium, and assessed for suppression of the MLR. Protein contents of each peak were determined by immunodiffusion and by sodium dodecyl sulfate (SDS)-polyacrylamide gel electrophoresis.

Cytotoxicity test of monocytes. A monocyte cytotoxicity test was performed in a modified two-stage complement-dependent microcytotoxicity assay, along with a B lymphocyte cytotoxicity test. Monocytes were incubated with NHS (negative control), anti-DR2 antiserum (T1193, positive control), anti-DQw1 antiserum (T847, positive control), and pregnancy sera $\mathrm{T} 1264$ and $\mathrm{T} 1295$, for $2 \mathrm{~h}$ at $37^{\circ} \mathrm{C}$, instead of $1 \mathrm{~h}$ as for the B cell cytotoxicity test. Serum T1193 was assigned to be a monospecific anti-DR2 antiserum, and serum T847 was also assigned to be a monospecific anti-DQw1 antiserum.

Binding test of monocytes with pregnancy sera T1264 and T1295. 1 $\times 10^{6}$ mononuclear cells were incubated with $100 \mu \mathrm{l}$ of NHS (control) and pregnancy sera $\mathrm{T} 1264$ and $\mathrm{T} 1295$, for $30 \mathrm{~min}$ at $37^{\circ} \mathrm{C}$. The cells were washed twice with RPMI 1640 medium and then reacted with fluorescein-conjugated goat anti-human Ig for $45 \mathrm{~min}$ at $4^{\circ} \mathrm{C}$. After they were washed, the cells were analyzed by a flow cytofluorometer (Orthospectrum III; Ortho Diagnostic Systems, Raritan, NJ).

Blocking test of antibody-binding on monocytes. A blocking experiment was performed as follows. $1 \times 10^{6}$ mononuclear cells were incubated with $100 \mu$ l of NHS (negative control), anti-DQw1 antiserum (T847, positive control), and pregnancy sera T1264 and T1295, for 30 min at $37^{\circ} \mathrm{C}$. The cells were washed twice with the RPMI medium and then reacted with fluorescein-conjugated monoclonal anti-DQ monomorphic antibody (Leu 10). After they were washed, the cells were analyzed by a flow cytofluorometer. In a blocking experiment using monoclonal antiDP monomorphic antibody (anti-FA, kindly supplied by Dr. F. H. Bach, University of Minnesota), $1 \times 10^{6}$ mononuclear cells were incubated with $100 \mu \mathrm{l}$ of NHS and pregnancy sera T1264 and T1295, respectively, for $30 \mathrm{~min}$ at $37^{\circ} \mathrm{C}$. After they were washed with RPMI 1640 medium, the cells were reacted with anti-FA antibody for $30 \mathrm{~min}$ at $37^{\circ} \mathrm{C}$. The cells were washed an additional two times with the RPMI medium and then reacted with fluorescein-conjugated goat anti-mouse Ig for $\mathbf{4 5} \mathrm{min}$ at $4^{\circ} \mathrm{C}$. After they were washed, those cells were analyzed by a flow cytofluorometer.

Suppression of the MLR. The degree of suppressive effects on the proliferative response of the lymphocytes in the MLR was calculated by the following formula: \% suppression $=(1-x / y) \times 100$, where $x$ is the response (cpm) of cells in the presence of monocytes treated with pregnancy serum and $y$ is the response (cpm) of cells in the presence of monocytes treated with NHS.

Statistical analysis. The percentage of suppression in MLR was tested for statistical significance by the $t$ test.

\section{Results}

DR specificity of stimulating cells in the MLR. The purified monocytes of responding donor M.N., who had HLA-A2, A24, B51, Bw52, C blank, DR2, and 2 DQw1,1 (homozygote, confirmed by a family study) were incubated with serum T1264, serum T1295, and NHS (control), for $30 \mathrm{~min}$ at $37^{\circ} \mathrm{C}$. After a complete washing, the monocytes were mixed with nonadherent cells ( $\mathrm{T}$ and $\mathrm{B}$ lymphocytes) of the same donor at approximately the original cell ratio. These reconstituted mononuclear cells as responding cells were co-cultured in MLR with mitomycin Ctreated mononuclear cells of several allogeneic stimulators. The results are presented in Tables I and II. In Table I, the monocytes were preincubated with serum T1264 and in Table II with serum T1295.

Interestingly, the proliferative response of the responding cells was markedly suppressed in reactions to all of the stimulating cells with DRw9. However, no suppression was seen in cultures with stimulating cells not having DRw9. Thus far, tests have been conducted with nine DRw9-positive stimulating cells and with nine DRw9-negative stimulating cells. In general, the degree of suppression was greater on DRw9 homozygous stimulating cells than on the heterozygous stimulating cells. We

Table VI. No Influence on Suppressive Effects of MLR in the Removal of Anti-DRw9 Antibody in Pregnancy Serum T1264

\begin{tabular}{|c|c|c|c|c|}
\hline $\begin{array}{l}\text { Responder M.N. } \\
\text { (DR2,2; DQw1,1) }\end{array}$ & $\begin{array}{l}\text { Stimulator H.H. } \\
\text { (DRw9,w9; DQw3,3) }\end{array}$ & \% Suppression & $\begin{array}{l}\text { Stimulator S.O. } \\
\text { (DRw4,-; DQw3,-) }\end{array}$ & \% Suppression \\
\hline Lymphocytes + M/NHS* & $12,176 \pm 2,015$ & & $17,163 \pm 1,098$ & \\
\hline Lymphocytes + M/1264ł & $3,644 \pm 516$ & $70^{\prime \prime}$ & $13,903 \pm 2,101$ & 19 \\
\hline Lymphocytes + M/1264 B.A. $\S$ & $3,926 \pm 1,203$ & $68^{11}$ & $13,459 \pm 1,014$ & 21 \\
\hline
\end{tabular}

\footnotetext{
* Monocytes preincubated with NHS (control). $¥$ Monocytes preincubated with serum T1264. § Monocytes preincubated with the absorbed serum T1264 by B cell lines (with DR4 and DRw9 specificity). Each monocyte preparation of responding donor M.N. was reconstituted with lymphocytes from the same donor. These reconstituted mononuclear cells as responding cells were co-cultured with stimulating cells. "Suppression, $P<0.02$.
} 
Table VII. MLR Suppressive Effects of Fractions from Serum T1295 by Anion Exchange Chromatography

\begin{tabular}{|c|c|c|c|c|}
\hline Responder M.N. (DR2,2; DQw1,1) & $\begin{array}{l}\text { Stimulator H.H. } \\
\text { (DRw9,w9; DQw3,w3) }\end{array}$ & \% Suppression & $\begin{array}{l}\text { Stimulator O.D. } \\
\text { (DRw8,-; DQw1,-) }\end{array}$ & \% Suppression \\
\hline Lymphocytes + M/NHS* & $19,493 \pm 1,951$ & - & $21,046 \pm 3,244$ & - \\
\hline Lymphocytes $+\mathrm{M} / \mathrm{IgG}^{+}$fraction $\ddagger$ & $3,055 \pm 401$ & $84^{\prime \prime}$ & $17,549 \pm 5,104$ & 17 \\
\hline Lymphocytes $+\mathrm{M} / \mathrm{IgG}^{-}$fraction§ & $17,738 \pm 2,264$ & 9 & $19,310 \pm 1,029$ & 8 \\
\hline
\end{tabular}

* Monocytes preincubated with NHS (control). $¥$ Monocytes preincubated with IgG-positive fraction. § Monocytes preincubated with IgG-negative fractions. "Significant suppression, $P<0.001$.

have further examined, using another DR2, homozygous responding cells from donor N.K., who had HLA-A24, Bw52, $\mathrm{DR} 2$, and DQw1. The same results were obtained as those from donor M.N.

Furthermore, we conducted tests to determine whether the lymphocyte proliferation was influenced by the preincubation of enriched T cells from the same donor with serum T1264 or T1295. The $T$ cells of a responding donor with DR2 homozygote were incubated with serum T1264 or T1295. Then the preincubated $\mathrm{T}$ cells were reconstituted with $\mathrm{B}$ cells and monocytes from the same donor. As shown in Table III (with serum T1295), the proliferative ability of lymphocytes was not decreased, even against the DRw9-positive stimulating cells.

Requirement for DR specificity of responding cells. One aspect of this research was to examine whether these suppressive effects could be seen on all the responding donors in MLR. We tested the suppressive effects of the MLR on other responding cells with different $\mathrm{DR}$ antigens, i.e., O.D. (DRw8,-; DQw1,-) cells or A.I. (DR1,1; DQw1,1) cells. As in the experiments using responding cells with DR2 homozygous cells from M.N., the monocytes of responding donor O.D., who had HLA A2, Aw33, B35, B44, Cw3, DRw8, and DQw1, were incubated with serum T1264 or T1295. As shown in Table IV (with serum T1264), the suppression of MLR was not observed when DRw8-positive responding cells were co-cultured with DRw9-positive stimulating cells as well as with other stimulating cells with a different DR phenotype. In the same way, the monocytes of responding donor A.I., who had HLA A24,24, B7,-, C7,-, DR1,1, and DQw1,1 (homozygote, confirmed by a family study), were incubated with serum T1264 or T1295. As with the monocytes of the DRw8-positive responding donor, suppression of MLR was not observed.
Absorption experiments on pregnancy serum with monocytes or $B$ cells. We next tested whether the suppressive effects could be expressed when the monocytes of a responding donor, which were incubated with the absorbed pregnancy serum by the same monocytes, were used in the allogeneic MLR. The monocytes of a responding donor with DR2 homozygote were incubated with pregnancy serum T1264 that had previously been absorbed by the monocytes from the same responding donor. Then the preincubated monocytes were reconstituted with lymphocytes from the same donor. Table V shows that these suppressive effects were abolished when the pregnancy serum was absorbed with monocytes from the responding donor.

The following absorption experiment was also carried out to exclude the possibility that the contaminated anti-DRw9 antibody in the pregnancy serum had an effect on the suppression of MLR. Pregnancy serum T1264 was absorbed with B cell lines (with DR4 and Drw9 specificity), and then the removal of antiDRw9 antibody from the serum was assessed by the standard lymphocyte cytotoxicity test. Thus, pregnancy serum was provided for the preincubation with monocytes of the responding donor. The results are presented in Table VI and show that the suppressive effect on the proliferative response of lymphocytes in the MLR was not affected by absorption of anti-DRw9 antibody in the pregnancy serum.

MLR suppressive effects in fractions of serum T1295 by anion exchange chromatography. Serum T1295 was fractionated on an anion exchange column. Molecules of the serum bound to the column were eluted using a linear $0.0-0.5 \mathrm{M} \mathrm{NaCl}$ gradient and separated into six fractiuns. Serum protein components in each fraction were examined by immunodiffusion. In addition, analysis of the first fraction by SDS-polyacrylamide gel electrophoresis revealed a single band as IgG molecules (data not

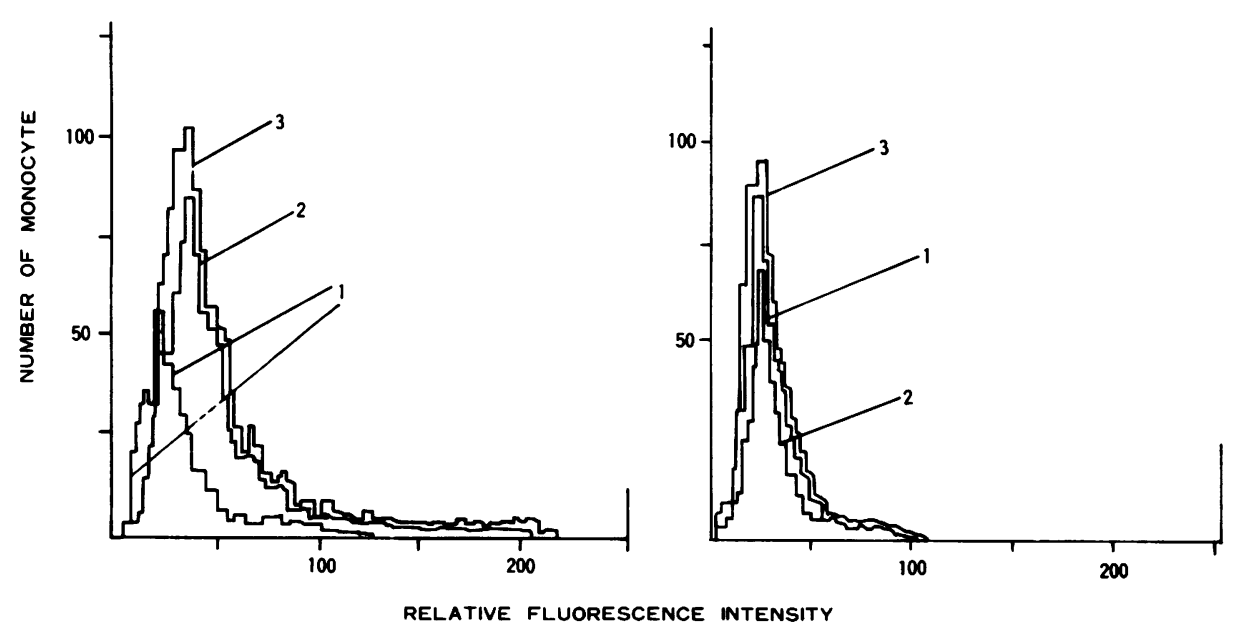

Figure 1. Binding test of monocytes with pregnancy serum T1264 or T1295. (Left) $1 \times 10^{6}$ mononuclear cells from donor M.N (DR2,2; DQw1,1) were incubated with $100 \mu \mathrm{l}$ of NHS (1), serum T1264 (2), and serum T1295 (3), respectively, for $30 \mathrm{~min}$ at $37^{\circ} \mathrm{C}$. After they were washed, the cells were reacted with fluorescein-conjugated goat anti-human Ig. (Right) $1 \times 10^{6}$ mononuclear cells from donor S.G. (DRw8,-; DQw1,-) were incubated with $100 \mu \mathrm{l}$ of NHS (1), serum T1264 (2), and serum T1295 (3), respectively, for $30 \mathrm{~min}$ at $37^{\circ} \mathrm{C}$, and then reacted with fluorescein-conjugated goat anti-human Ig. Each of the reacted monocytes was analyzed by a flow cytofluorometer. 
Table VIII. Reaction Pattern of Each Serum with Monocytes and B Lymphocytes from Donor M.N. (DR2,2; DQw1,1)

\begin{tabular}{|c|c|c|c|c|c|c|c|c|c|c|c|c|c|c|c|c|c|c|c|c|}
\hline & \multicolumn{4}{|c|}{ NHS } & \multicolumn{4}{|c|}{$\begin{array}{l}\text { T1193 (anti-DR2 } \\
\text { antiserum) }\end{array}$} & \multicolumn{4}{|c|}{$\begin{array}{l}\text { T847 (anti-DQw1 } \\
\text { antiserum) }\end{array}$} & \multicolumn{4}{|c|}{$\mathrm{T} 1264$} & \multicolumn{4}{|c|}{ T1295 } \\
\hline & 1 & $2 x$ & $4 x$ & $8 x$ & 1 & $2 x$ & $4 \times$ & $8 x$ & 1 & $2 x$ & $4 \times$ & $8 x$ & 1 & $2 \times$ & $4 \times$ & $8 x$ & 1 & $2 x$ & $4 \times$ & $8 \times$ \\
\hline Monocytes & 1 & 1 & 1 & 1 & 8 & 8 & 4 & 1 & 1 & 1 & 1 & 1 & 1 & 1 & 1 & 1 & 1 & 1 & 1 & 1 \\
\hline B Lymphocytes & 1 & 1 & 1 & 1 & 8 & 8 & 8 & 6 & 8 & 8 & 6 & 1 & 1 & 1 & 1 & 1 & 1 & 1 & 1 & 1 \\
\hline
\end{tabular}

Each serum was serially diluted to $1: 8$. Percent of cytotoxicity score: $8>70 ; 6>40 ; 4>20 ; 2>10$; and $1<10$ dead cells.

shown). A suppressive activity was found to have been eluted in the first fraction, which corresponds closely to IgG molecules, as shown in Table VII. In contrast, subsequent IgG-negative fractions had no effect on MLR responsiveness.

Analysis of a factor in pregnancy sera T1264 and T1295 by a binding test. As shown in Fig. 1 (left), when the monocytes of donor M.N. (DR2 and DQw1 homozygote) were incubated with serum T1264 or T1295, human Ig molecules were observed, using fluorescein-conjugated goat anti-human Ig, to bind on the surface of the monocytes. In contrast, when the monocytes from donor S.G. (DRw8 and DQw1 heterozygote) were incubated with serum T1264 or T1295, no binding of human Ig was observed on the monocytes (Fig. 1, right).

Reactivity of antibodies in serum T1264 and T1295 against monocytes. The following study was performed to examine whether these antibodies reacted with DR, DQ, and DP determinants on monocytes from donor M.N. Table VIII shows the results of a monocyte cytotoxicity test. Neither serum T1264 nor T1295 gave positive cytotoxic reactions on the monocytes. However, some recently accumulated data indicated that antiDQ antibody could not be detected on monocytes by a serological microcytotoxicity test. Therefore, a blocking study on monocytes was performed using a fluorescein-conjugated monoclonal monomorphic antibody, Leu 10, which had been shown to react selectively with DQ antigen. As shown in Fig. 2 (left), anti-DQw1 alloantiserum (serum T847) had blocking effects on the binding activity of Leu 10. In contrast, sera T1264 and T1295 had no blocking effect on the binding of Leu 10 (Fig. 2, right).

A blocking experiment using a monoclonal anti-DP monomorphic antibody (anti-FA) was also performed (Fig. 3). Monocytes pretreated with T1264 or T1295 were found to have re- duced binding capacity with the monoclonal antibody anti-FA. These results suggested that sera T1264 and T1295 contain antibodies to the DP determinants on monocytes of donor M.N., but not to the DR determinants and the DQ determinants.

Evidence that these suppressive effects were dependent on the number of monocytes used. The MLR responses were examined with various numbers of preincubated monocytes of responding cells (Fig. 4). MLR responses were more suppressed in cultures in which a greater number of preincubated monocytes with serum T1295 in responding cells from donor M.N. were used. No suppressive effects could be seen in the experiment using an equal number of preincubated monocytes with NHS to lymphocytes in responding cells.

\section{Discussion}

Stimulation in MLR represents a response to gene products of the HLA-D region in the major histocompatibility complex (25). The $D$ region appears to encode a number of antigens including the DR, DQ, and DP antigens.

Many previous investigators have reported that alloimmune sera have inhibitory effects on the proliferative response in allogeneic MLR. They have thought that the inhibitory effects were based on the blocking of DR antigens on stimulating cells or responding cells by DR antibodies in the sera.

Pregnancy sera were examined for their possible suppressive effects that were mediated by monocytes on allogeneic MLR. It has been observed that the purified monocytes of responding donor M.N. preincubated with heat-inactivated pregnancy serum T1264 or T1295 for a fixed period of time expressed allogeneic suppressive effects on the proliferative response of the lympho-

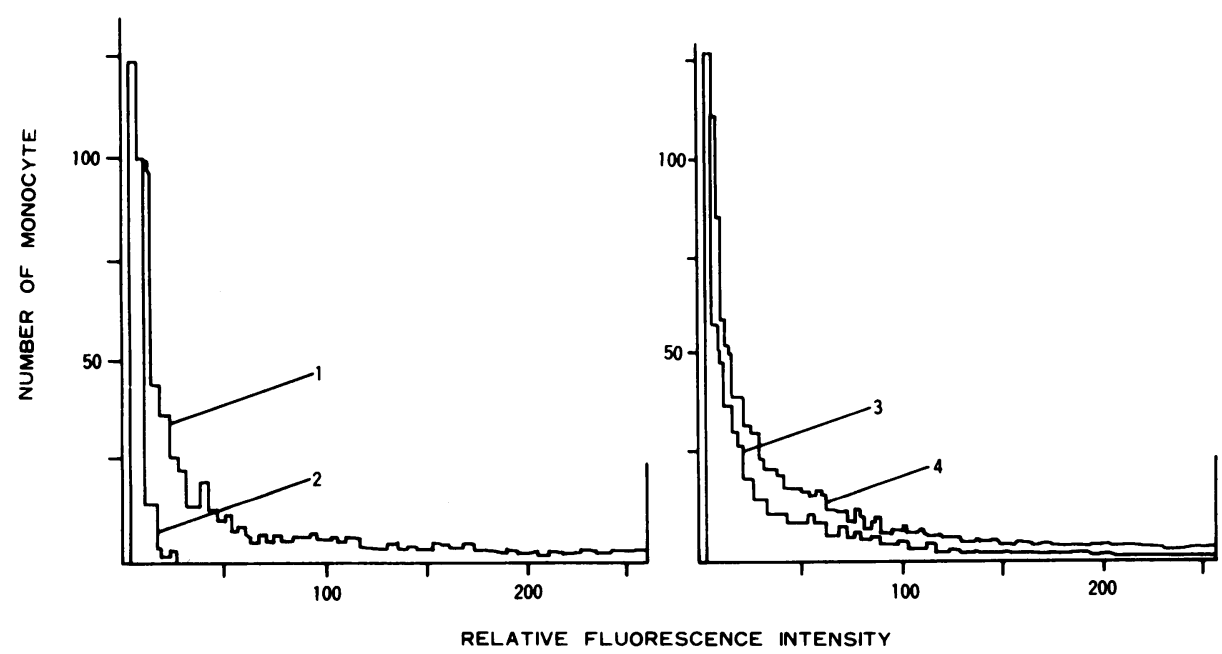

Figure 2. Blocking test of antibody binding on monocytes with pregnancy serum T1264 or T1295 using monoclonal antibody Leu $10.1 \times 10^{6}$ mononuclear cells from donor M.N. (DR2,2; $\mathrm{DQw1}, 1)$ were incubated with $100 \mu \mathrm{l}$ of NHS (1), anti-DQw1 antiserum T847 (2), serum T1264 (3), and serum T1295 (4), respectively, for $30 \mathrm{~min} 37^{\circ} \mathrm{C}$. After they were washed, the cells were reacted with fluorescein-conjugated Leu 10. Each of the reacted monocytes was analyzed by a flow cytofluorometer. 


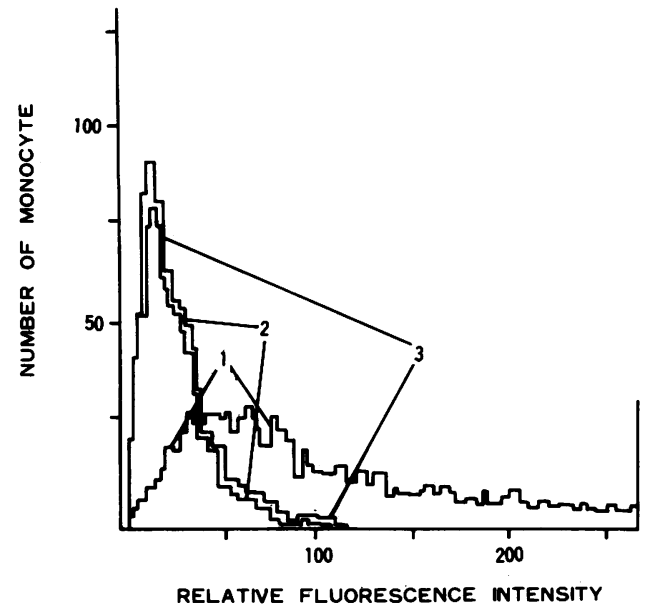

Figure 3. Blocking test of monocytes with pregnancy serum T1264 or T1295 using monoclonal anti-DP monomorphic antibodies (anti-FA). $1 \times 10^{6}$ mononuclear cells from donor M.N. (DR2,2; DQw1,1) were incubated with $100 \mu$ l of NHS (l), serum T1264 (2), and serum $\mathrm{T} 1295$ (3), respectively, for $30 \mathrm{~min}$ at $37^{\circ} \mathrm{C}$. After they were washed, the cells were reacted with anti-FA followed by fluorescein-conjugated goat anti-mouse Ig. The reacted monocytes were analyzed by a flow cytofluorometer.

cytes from the same donor in the allogeneic MLR. These suppressive effects were observed to be specific for DRw9- or DRw9associated gene products on stimulating cells. It is possible that the contaminated anti-DRw9 antibody in the pregnancy serum blocks the DR determinants on stimulating cells. However, in our studies, the pregnancy serum was completely washed out

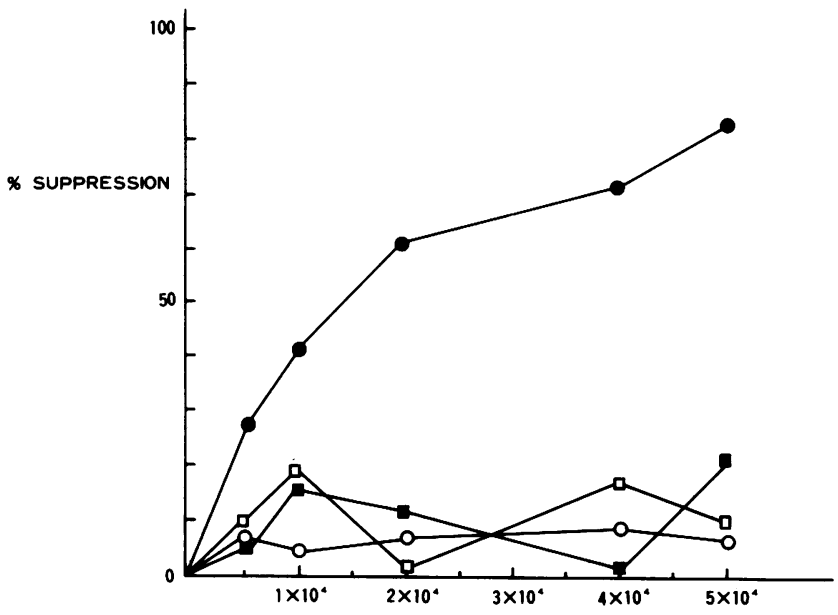

NUMBER OF PREINCUBATED MONOCYTES/CULTURE

Figure 4. The suppressive effects in the MLR with an increasing number of preincubated monocytes in responding cells. Stimulating cells $(50,000)$ and lymphocytes $(50,000)$ were co-cultured, with an increasing number of preincubated monocytes $(5,000-50,000)$ as responding cells. Responding cells from donor M.N. (DR2 and DQw1 homozygote) were used, in which monocytes were preincubated with NHS (0) or serum T1295 (๑). Different responding cells from donor O.D. (DRw8 and DQw1 heterozygote) were used, in which monocytes were preincubated with NHS (口) or serum T1295 (๘). Stimulating cells from donor S.T. (DR4 and DRw9) were used. \% suppression = [response (cpm) of cells in the presence of monocytes treated with serum T1295 or NHS/response (cpm) of cells in the absence of the treated monocytes (response of nonadherent cells)] $\times 100$. after incubation with monocytes. Furthermore, the suppressive effects were not affected by removal of anti-DRw9 antibody in the pregnancy serum. Accordingly, the suppressive effects were not from the blocking of DRw9 determinants on stimulating cells. Additionally, these suppressive effects were shown on the monocytes of a DR2-positive responding donor, but not on the monocytes of a DR2-negative responding donor. Moreover, it could be that the separated IgG fraction from the pregnancy serum proved to bind significantly more Ig molecules than the controls. These suppressive effects were not observed when the enriched $T$ cells from the same DR2-positive responding donor were incubated with serum T1264 or T1295.

Based on these observations, it can be assumed that monocytes of DR2-positive responding cells react with antibodies (IgG class) in pregnancy serum T1264 or T1295 through specific receptors or determinants on the monocytes and that the reacted monocytes provide a regulatory signal for $\mathrm{T}$ cell proliferation to DRw9-positive stimulating cells. This hypothesis is further supported by our study in which suppressive effects were abolished when the absorbed pregnancy serum by monocytes of the responding donor were used. In our experiments, pregnancy sera T1264 and T1295 were found by both a monocyte cytotoxicity test and a blocking test to contain no antibodies to DR or DQ antigen on monocytes of the responding donor. Therefore, the suppressive effects of the pregnancy sera are not consistent with the concept that anti-DR or anti-DQ antibody in the serum blocks the DR or DQ antigen on monocytes of a responding donor. In contrast, the monocytes pretreated with the sera were found to have reduced binding capacity with a monoclonal antiDP monomorphic antibody to DP determinants on monocytes. Accordingly, it may be possible that monocytes are activated for their suppressive activity to MLR by the reaction of DP determinants on monocytes with antibodies in the sera.

Although the immunosuppiessive effects in the human allogeneic MLR may be a complex of different immunosuppressive mechanisms, the present study found that factors other than suppressor cells may also play an important role in the suppression of the allogeneic MLR. Based on studies of the mouse model, Nagarkatti et al. (5) have suggested that an antiidiotypic antibody induced by transfusion can block the antigen-specific receptor on the T cells and cause suppression of the recipient's response against a donor's alloantigens in MLR. In contrast, our study demonstrates another suppression mechanism of the allogeneic MLR based on the reaction of antibodies in the pregnancy serum with specific molecules on monocytes. In the suppression mechanism we propose, monocytes react with antibodies in the pregnancy serum through specific molecules on monocytes that are distinct from DR or DQ determinants on monocytes of the responding donor. Consequently, the monocytes that were reacted with the antibodies provide a regulatory signal for $\mathrm{T}$ cell proliferation. As a result, the T cell proliferation in MLR for certain types of stimulators was suppressed. Further studies are in progress to examine whether these suppressions were expressed by the reaction of monocytes with anti-DP antibodies or with other antibodies (such as antiidiotypic antibody) in the pregnancy sera.

It is an immunological paradox to see a suppression of allogeneic MLR respond to DRw9-positive stimulating cells along with anti-DRw9 antibody in the pregnancy sera. This suppression might be expressed to balance the maternal immune response to fetal antigens that provide for fetal well-being.

Although more studies are necessary before a definitive conclusion regarding the role of monocytes and antibodies in preg- 
nancy sera can be reached, it may be that a suppression mechanism mediated by monocytes and antibodies (distinct from anti-DR antibody and anti-DQ antibody) in the pregnancy sera also plays an important role, along with a variety of other suppression phenomena.

\section{Acknowledgments}

We wish to express our gratitude to all the volunteer blood donors, without whom this work would not have been possible. We are grateful to Ms. Junko Kimigafukuro for typing the manuscript.

\section{References}

1. Medawar, P. B., and E. Simpson. 1975. Thymus-dependent lymphocytes. Nature (Lond.). 258:106-108.

2. Nelson, D. S. 1973. Production by stimulated macrophages of factors depressing lymphocyte transformation. Nature (Lond.). 246:306307.

3. Ptak, W., and R. K. Gershon. 1975. Immunosuppression effected by macrophage surfaces. J. Immunol. 115:1346-1350.

4. Ordal, J., S. Smith, D. Ness, R. K. Gershon, and F. C. Grummet. 1976. IgM-mediated, T cell independent suppression of humoral immunity. J. Immunot. 116:1182-1187.

5. Nagarkatti, P. S., S. Joseph, and D. P. Singal. 1983. Induction of antibodies by blood transfusions capable of inhibiting responses in MLC. Transplantation (Baltimore). 36:695-699.

6. Folch, H., and B. H. Waksman. 1974. The splenic suppressor cell. I. Activity of thymus-dependent adherent cells: changes with age and stress. J. Immunol. 113:127-139.

7. Folch, H., and B. H. Waksman. 1974. The splenic suppressor cell. II. Suppression of mixed leukocyte reaction by thymus-dependent adherent cells. J. Immunol. 113:140-150.

8. Englemann, E. G., J. McMichael, and H. O. McDevitt. 1978. Suppression of the mixed lymphocyte reaction in man by a soluble Tcell factor. J. Exp. Med. 147:1037-1043.

9. Engelmann, E. G., and H. O. McDevitt. 1978. A suppressor T cell of the mixed lymphocyte reaction specific for the HLA-D region in man. J. Clin. Invest. 61:828-838.

10. Smolen, J. S., S. O. Sharrow, J. P. Reeves, W. A. Boegel, and A. D. Steinberg. 1981. The human autologous mixed lymphocyte reaction. I. Suppression by macrophages and T cells. J. Immunol. 127: 1987-1993.

11. Laughter, A. H., and J. J. Twomey. 1977. Suppression of lym- phoproliferation by high concentrations of normal human mononuclear leukocytes. J. Immunol. 119:173-179.

12. Hausman, P. B., H. V. Raff, R. C. Gilbert, L. J. Picker, and J. D. Stobo. 1980. T cells and macrophages involved in the autologous mixed lymphocyte reaction are required for the response to conventional antigen. J. Immunol. 125:1374-1379.

13. Huber, C., H. Fink, W. Leibold, F. Schmalzl, P. A. Peterson, L. Klareskog, and H. Braunsteiner. 1981. The role of adherent HLA-DR ${ }^{+}$ mononuclear cells in autologous and allogeneic MLR. J. Immunol. 127: 726-731.

14. Beale, M. G., R. P. MacDermott, M. C. Stacey, G. S. Nash, B. H. Hahn, M. V. Seiden, S. L. B. Jacobs, and L. S. P. Loewenstein. 1980. Stimulating cell types in the autologous mixed leukocyte reaction in man. J. Immunol. 124:227-232.

15. Lohrmann, H. P., L. Novikous, and R. G. Graw. 1974. Stimulatory capacity of human $\mathrm{T}$ and $\mathrm{B}$ lymphocytes in the mixed leukocyte culture. Nature (Lond.). 250:144-146.

16. Rode, H. N., and J. Gordon. 1974. Macrophages in the mixed leukocyte culture reaction (MLC). Cell. Immunol. 13:87-94.

17. Levis, W. R., and J. H. Robbin. 1970. Function of glass-adherent cells in human mixed lymphocyte cultures. Transplantation (Baltimore). 9:515-518.

18. Blomgren, H. 1977. Subpopulations of cells involved in the human mixed lymphocytes culture response. Scand. J. Immunol. 6:857-866.

19. Potter, M. R., and M. Moore. 1977. Human mixed lymphocyte culture using separated lymphocyte populations. Immunology. 32:359365 .

20. Albrechtsen, D., and M. Lied. 1978. Stimulating capacity of human lymphoid cell subpopulations in mixed lymphocyte cultures. Scand. J. Immunol. 7:427-434.

21. Mann, D. L., and L. Abelson. 1980. Monocyte function in mixed lymphocyte reactions. Cell. Immunol. 56:357-364.

22. Muchmore, A. V., J. M. Decker, and D. L. Mann. 1982. Evidence that antisera that react with products of the human HLA-DR locus may block in vitro antigen-induced proliferation by inducing suppression. $J$. Immunol. 128:2063-2066.

23. Muchmore, A. V., M. Megson, J. M. Decker, P. Knudsen, D. L. Mann, and S. Broder. 1983. Inhibitory activity of antibodies to human Ia-like determinants. J. Immunol. 131:725-730.

24. Danilovs, J., P. I. Terasaki, M. S. Park, and G. Ayoub. 1980. B lymphocyte isolation by thrombin nylon-wool. In Histocompatibility Testing. P. I. Terasaki, editor. University of California Press, Los Angeles. 287-288.

25. Thorsby, E., and A. Piazza. 1975. Joint Report from the VI International Histocompatibility Workshop Conference. In Histocompatibility Testing. F. Kissinger-Nielsen, editor. Munksgaard, Copenhagen. 414-457. 